\title{
Almanaques de locos: la representación popular de la locura en la España de posguerra.
}

Almanaques de Locos: Popular depiction of madness in Spain's postwar period.

\author{
Andrés Porcel Torrens a. \\ ${ }^{a}$ Psiquiatra. Departamento de Salud Dr. Peset. Conselleria de Sanitat. Valencia, España.
}

Correspondencia: Andrés Porcel Torrens (porceltorrens@hotmail.com)

RESUMEN: Los Almanaques de Locos* fueron revistas de historieta publicadas en el período 1946-1963. Contaban con una amplia difusión y se trataba de publicaciones de humor cuyo contenido se centraba en una visión cómica de la locura, dando lugar a numerosas representaciones sobre los trastornos mentales, su asistencia y sus profesionales. El análisis de sus contenidos ofrece una interesante visión de las ideas, actitudes y conocimientos que el público general de su época tenía sobre estos temas. El presente trabajo pretende brindar una perspectiva general sobre los contenidos de los Almanaques y resaltar su valor como testimonio histórico.

PALABRAS CLAVE: locura, historieta, historia social, psiquiatría.

\section{Introducción}

La perspectiva cómica de la locura es una tradición bien asentada en el imaginario occidental. Las "fiestas de locos" de las postrimerías del Medioevo son la expresión abierta de un acercamiento a los trastornos mentales desde una visión cómica, remarcando a través del humor la distancia que debe establecerse entre el loco y quienes se contemplan como los miembros ortodoxos de la sociedad (1). Desde los inicios de las primeras instituciones específicas para enfermos mentales, la asistencia -o más bien la custodia- incluía, al menos en tiempos señalados en el calendario, la exhibi-
ABSTRACT: Almanaque de Locos* was a comic book edited in Spain between 1946 and 1963. Had a wide circulation and was humorous publications whose content is focused on a comic vision of madness, resulting in numerous representations about mental disorders, attendance and professional. The analysis of its contents provides an interesting insight into the ideas, attitudes and knowledge that the general public of his day had on these issues. This paper aims to provide an overview of the contents of the Almanacs and highlight their value as historical testimony.

KEY WORDS: madness, cartoon, social history, psychiatry.

ción de los aspectos más grotescos o sorprendentes de los asilados (2). Aun cuando desde la Ilustración esta exhibición va desapareciendo, cubierta de pudor, los chistes "de locos" continúan, hasta fechas recientes, como un recurso -casi un subgénero- habitual en el repertorio de lugares comunes de la comicidad.

La cultura de masas integra a partir de los primeros años del siglo XX los contenidos más arraigados de la cultura popular con la incorporación de nuevos elementos, una amalgama de vulgarización de saberes de la cultura oficial y de transformaciones de las formas académicas del arte y la comunicación para hacerlas aptas al consumo de un público que por vez primera

\footnotetext{
* Varios de los "Almanaques de Locos" completos en formato digital están disponibles en Óscar Martínez Azumendi (2007). Imaginario social a través del humor. Accesibles en http://antigua.ome-aen. org/CRONICON/HUMOR.HTIM
} 
en la historia tiene acceso a representaciones culturales hasta entonces reservadas a una escasa minoría letrada. Más aún que el periodismo escrito y la literatura, son cine e historieta los medios de expresión que tienen más amplia difusión, revelándose a partir de las primeras décadas del siglo como las expresiones más representativas de una gigantesca transformación en la comunicación cultural.

A partir de los años treinta y sobre todo en las tres décadas siguientes a la guerra civil, las publicaciones de historietas -los tebeos- conquistan en nuestro país un lugar de primer orden en los medios de masas, superando en mucho al público infantil al que teóricamente se destinan. Para millones de lectores, los tebeos proporcionan las primeras -y a menudo las únicas- representaciones de lugares, hechos o ideas que incorporan, de modo apenas consciente, al bagaje que conformará su visión del mundo. Como medio de comunicación, estas publicaciones reflejan en buena parte los testimonios, los estereotipos, las aspiraciones y los valores comunes a la sociedad donde se difunden. La doble lectura -textual e icónica- que la historieta ofrece, multiplica la fuerza de los mensajes y facilita un proceso de asimilación de los mismos que tiene mucho de automático.

En la España de postguerra, la industria editorial de tebeos se concentra en unas pocas empresas, ubicadas en su mayoría en Barcelona o en Valencia. A través de sus publicaciones se definen grupos de creadores que llegan a constituir escuelas con un estilo reconocible. La Editorial Valenciana, fundada en los años treinta, se constituye en los años siguientes como una de las empresas capitales del ramo. El éxito de títulos como Jaimito, Roberto Alcázar o El Guerrero del Antifaz la ubica en un lugar principal entre las editoriales y facilita la distribución universal de sus productos, que conocen en esos años una difusión popular que resulta difícil exagerar. José Soriano Izquierdo, un dibujante cuya carrera se inició en el período prebélico, tras escapar en lo posible a las represalias que le acarreó su implicación antifranquista, ocupó desde los años cuarenta el cargo de director artístico, contribuyendo decisivamente a elaborar la imagen característica de las publicaciones y a aglutinar un grupo de jóvenes creadores que alcanzarían una etapa de brillantez en los años siguientes, conquistando durante décadas el favor del público. Soriano es responsable de la orientación de contenidos en los semanarios, además de colaborar activamente en los mismos con sus propias creaciones (3).

Fue probablemente una iniciativa de Soriano la que llevó a la editorial al lanzamiento de una publicación singular, heredera directa del abordaje cómico de la locura: el Almanaque de Locos. Se editaron estas revistas en cuadernos de 16 páginas, de periodicidad anual, aparecidos en fechas navideñas, aprovechando la tradición de editar los almanaques como números extraordinarios de las colecciones en curso. El primer Almanaque de Locos apareció en 1946, publicándose todos los años hasta 1952. La aparición se interrumpió hasta la salida de los dos últimos ejemplares en 1962 y 1963, lo que hace un total de nueve números. Las revistas se consagraban por entero a historietas y chistes "de locos", muy breves, realizadas por los dibujantes habituales de la editorial, entre los que destacan el propio Soriano, Jesús Liceras, José Palop, Alamar, José Grau, Enrique Pertegás, Serafín y otros. El denominador común de todas las historias era su relación con la locura, tomada de forma más o menos directa, pero siempre presente. La trayectoria de los Almanaques se interrumpió, según relató el propio Soriano cuando tras varios años de aparición se le invitó a visitar el psiquiátrico de Valencia, para extraer nuevas inspiraciones. Allí quedó tan impresionado por la miserable condición de los enfermos que decidió suspender la publicación, arrepintiéndose de haber tratado de manera tan frívola una circunstancia que se le reveló dramática (4).

En los años de la posguerra, durante la vida de los Almanaques de Locos, la asistencia 
psiquiátrica se concentraba fundamentalmente en los manicomios, habitualmente de gran tamaño, cuya responsabilidad corría a cargo de diversas instituciones -en gran número de casos, órdenes religiosas, en otros diputaciones provinciales- sin una coordinación entre los centros ni una política asistencial común. La creación del Patronato Nacional de Asistencia Psiquiátrica, con pretensiones de unificar y organizar la asistencia, no llegó hasta 1955, y su trayectoria estuvo lejos de alcanzar los fines inicialmente propuestos. Los manicomios privados -eufemísticamente llamados casas de salud, o de reposo- cubrían la demanda de los enfermos más pudientes, quienes tenían también acceso a la atención ambulatoria, prácticamente reservada al ámbito de la medicina privada $(5,6)$. Es esta dura realidad la que aparece reflejada de manera más o menos directa en las historietas del Almanaque de Locos. La publicación ofrece así tanto una representación directa como sobre todo un reflejo de las ideas populares, las actitudes, los prejuicios y los temores que rodean a la enfermedad mental y a los profesionales a su cargo. La doble vertiente, gráfica y literaria, de la historieta enriquece su valor como testimonio histórico. El presente trabajo pretende brindar un breve recorrido por los Almanaques de Locos y rescatar del olvido una porción de la memoria popular.

\section{Representaciones de la locura}

La denominación de los trastornos mentales es normalmente sencilla y unívoca, y la forma más repetida de referirse a ellos es con el término de locura, y el de loco para el enfermo. Se trata de un término que designa de forma general, sin entrar en matices sobre características diferenciales entre unas representaciones y otras. Las palabras tienen en las historietas cómicas una acepción claramente festiva, mientras en una trama de contenido dramático o aventurero adquieren un tono de amenaza. A menudo el adjetivo de loco se emplea simplemente para calificar cualquier acto de desmesura o una simple desviación de las normas sociales y de conducta esperables: puede merecer el calificativo el hecho de conducir un automóvil de forma imprudente, bailar de manera inusual o invertir un tiempo desmesurado en la pesca. El uso no difiere del asentado desde al menos la Baja Edad Media, tanto en lenguaje coloquial como en términos literarios, como lo han señalado estudios específicos referidos a épocas mucho más remotas (7).

Otros términos que designan a los pacientes pueden ser los de mochales, chiflado o chalado, mas coloquiales, siempre entendidos de manera cómica y bien familiares para el lector, a quien no se necesita ofrecer aclaraciones(8). En alguna ocasión encontramos la palabra "esquizofrénico" bien que entendida como un sinónimo de locura sin más matizaciones, como cuando Soriano se refiere a los "Pronósticos esquizofrénicos para el año 1949". La palabra "complejo" designa trastornos menores, que no conllevan la pérdida de la razón, como en el chiste de Edgar donde un paciente que alude al complejo de inferioridad se nos presenta en el ámbito de una consulta privada. El término tuvo extraordinaria fortuna a partir de los años cuarenta y en la cultura popular puede entenderse como un sinónimo de neurosis (9).

La representación gráfica del loco sigue un patrón muy codificado, convirtiendo su figura en directamente reconocible: los ademanes bruscos, exagerados, reforzando el movimiento con líneas cinéticas, en posturas forzadas; el gesto extraviado, casi siempre jovial -si no iracundo-, mostrando los dientes, la mirada estrábica, desorbitada; el atuendo extravagante o descuidado, el tocado característico de sombrero de papel o de objetos absurdos a modo de gorro -el embudo, el colador- transmiten implícitamente una imagen que vulnera la lógica de aspectos y conductas. Incluso en una historieta de Alamar, de 1950, ¿Qué era usted antes de 
volverse loco? los personajes, todavía cuerdos, se muestran ya según los cánones gráficos de la locura. El que en ocasiones los internos lleven prendida en la espalda la silueta de un muñeco de papel remite directamente a la denominación de inocentes, palabra con que se señalaba el retraso mental durante la Baja Edad Media. $\mathrm{Y}$ es que toda la iconografía se remonta a una tradición tardo medieval, donde encontramos imágenes arquetípicas similares a las de la historieta, pervivencia de estereotipos firmemente arraigados en la cultura popular (10). En la portada de Soriano para el almanaque de 1949, las figuras que asoman por la valla no sorprenderían en una pintura flamenca del siglo XV.

Son mucho menos frecuentes las ocasiones en que la apariencia del enfermo puede confundirse con la del sano. En las historietas serias este recurso se convierte en motor de la acción, como en Un extraño caso, de Grau (1949), en que un juez que emite sentencias inexplicables, que se atribuirán a su trastorno, tarda mucho en ser descubierto. En otras, la propia semejanza hará que se conduzca por error al manicomio a cuerdos a quienes se confunde con los locos, como en Se ha escapado un loco, de 1949. El profesional se atribuye sin embargo la facultad de diferenciarlos, como en la historieta Un loco de cuidado, de Cartús (1949) cuando el psiquiatra piensa ante el paciente que "este loco es auténtico con la cara de chalao que tiene".

Encontramos un núcleo común en todas las acciones representadas como propias de los dementes: la pérdida de la lógica, que puede sustituirse por una suerte de lógica paralela, ajena a la convencional. Los ejemplos son muy numerosos. Los locos preferirán tirarse por el trampolín de una piscina vacía que por el de una llena; se disputan como una novela la lectura de una guía telefónica; se columpian en el alero de una ventana, sorprendiéndose cuando se caen; pretenden medir la longitud de un sonido; son incapaces de distinguir a los hombres de las mujeres cuando van desnudos; se colocan en la vía del tren para ser arrollados con la idea de gastar una broma... el carácter absurdo se repite invariablemente desde el primer almanaque de 1946 al de 1963, sin variaciones entre los diversos autores. En alguna ocasión, la locura se significa directamente como la inversión de la lógica común, como en las ilustraciones de Soriano para las portadas de 1949 y 1951, que muestran a los personajes principales literalmente cabeza abajo.

La índole festiva con que se representa esta ausencia de juicio no excluye el carácter de amenaza que la acompaña. Por definición, el loco es peligroso. Aún sin la forma dramática que adquiere en los tebeos de aventuras, se insiste constantemente en esta peligrosidad. Las acciones de los enfermos son imprevisibles, y reiteradamente muestran la tendencia a ejercer una violencia falta de sentido, disfrutando al golpear o matar sin que medie provocación alguna. En la historieta El certificado, de Liceras (1952) un enfermo al que se le dan "vacaciones" en el manicomio apenas sale golpea la cabeza de un transeúnte, retorciéndose de risa y exclamando que " ¿jo, jo, jo! Jua jua jua! ¡Si todos son como este, voy a pasar unas vacaciones fenómeno!". En La camisa de fuerza, de Palop(1950), la criada advierte que "al señorito le ha cogido la locura otra vez y está rompiendo todo", en el almanaque de 1948 un paciente decapita a otro para demostrarle que no tiene sangre azul; en Reportaje loco, de Serna (1949) un periodista al que le encargan visitar un "club de locos" es agredido por sus miembros. El personaje de Ayné con el expresivo nombre de Cortadelli Cabezoni (1950) es un paciente al que se otorga permiso en el manicomio, y armado de unas tijeras pretende cortar lo que encuentre a su paso. En varias historietas se difunde por radio el aviso de la fuga de un interno, recomendando incluso a la población que se abstenga de salir a la calle, hasta que sea de nuevo cazado.

Pese a los esfuerzos por distinguir y aislar a la locura, es un tópico repetido en los almanaques el presentar su proximidad con la vida 
cotidiana, insistiendo en desdibujar los límites que la separan de la cordura. El presentar actuaciones admitidas como normales como cercanas a las de los locos es un recurso que se reitera de una u otra forma en todos los ejemplares. En una breve obra de Soriano de 1947, un interno tras leer el periódico reacciona colocando el letrero del manicomio de forma que caiga sobre el exterior, exclamando "¿Qué no nos confundan! ¡El manicomio está ahí fuera!". Todo lo que se aleje de la ortodoxia burguesa es susceptible de entrar en la locura: La poesía -en una historieta de Edgar de 1950, un poeta extasiado con la naturaleza acaba conducido al manicomio- el arte moderno, los bailes de moda, el existencialismo -que aparece en la red del loquero en la portada de 1950- el amor o incluso las pretensiones de los quinielistas, como Soriano retrata en ;Se han escapado cuatro locos!, de 1948, cuando cualquier personaje que muestre una actitud juzgada como extrema es capturado por los loqueros. En la ilustración de Liceras Ni están todos los que son (1949) el autor incluye entre los candidatos al encierro al enamorado, al poeta, al espectador apasionado, al pintor, al filatélico, y por fin a sí mismo, insertando la sinrazón en lo cotidiano. La historieta de Pertegás Manías de los grandes hombres (1950) incide en la misma idea, señalando las extravagancias de personajes célebres como Domiciano, Richelieu, Haendel o Rembrandt, cuya cordura deja fuera de toda duda.

A pesar de su brevedad, en algunas obras pueden detectarse ideas sobre las posibles causas de la locura. La más difundida es la atribución de la pérdida de la razón a un choque emocional, bien como trauma o como pasión extremada: en El destino de divierte (1948) el guionista Sellés explica que unos de sus personajes "está loco a causa de un desengaño amoroso odia a todas las mujeres", lo que explica su implicación en el asesinato de una vecina. También una idea que llega a hacerse obsesiva puede desencadenar la demencia, como cuando en La quiebra del Central Bank (1952), el contable no consigue cuadrar el balance, terminando ingresado en el psiquiátrico. De forma más festiva, en Las barbas del abuelo (1949) el dudar sobre cómo colocar la barba en la cama desencadena un acceso de furor demencial. Junto a las pasiones, los golpes en la cabeza se identifican también como causa de enajenación, como en Contacto (1947) cuando tras una paliza el agredido afirma ser Catalina de Médicis.

La locura se demuestra por sus actos, que el observador transforma en síntomas. Aunque de forma a menudo indirecta, en los almanaques se reportan algunos de los que se consideran más característicos. Se ha aludido ya a la exaltación y a la violencia, dos de los rasgos que acompañan gran parte de las representaciones de los locos. En cuanto a las ideas, además de las sustentadas en la ausencia de lógica, encontraremos como una de las principales el hecho de que el demente piensa ser otra persona distinta de la que es. Muy a menudo creerá ser un personaje histórico: entre ellos, el más repetido es Napoleón, hasta tal punto que el atuendo propio de su figura se entiende ya como el signo icónico de la locura. En una viñeta de Palop de 1962, todos los internos lucen el gorro napoleónico, excepto uno de quien se dice que "está en observación porque no se cree Napoleón". El delirio se extiende también a considerarse un objeto, lo que da lugar a numerosos chistes: los pacientes con el "mal de la higuera" se dejan caer de la copa de un árbol; en las Chispas dementes (1950) de Palop un enfermo vestido como una farola se alegra de que nadie a su alrededor se considere perro, mientras a su lado vemos pacientes vestidos de cafetera o de gallina; Edgar dibuja en 1948 un asilado dentro de una olla al fuego, porque piensa ser un garbanzo. Los ejemplos son numerosísimos. El término "complejo" además de aludir a los trastornos neuróticos puede referirse también al mismo delirio de identidad: "complejo de ladrón", o "complejo de pájaro" tienen esta acepción. Encontramos también alusiones a las 
"manías de grandeza" en los pacientes que se creen millonarios, y a la "manía persecutoria" en un chiste de Edgar de 1951. El exceso en las facultades se relaciona también con la excentricidad, juzgándose -de forma benévola- como una forma menor de trastorno, tal como lo ilustra Pertegás en Genialidades que parecen locuras (1948) aludiendo a las extravagancias de grandes personajes de la historia o en $U n$ genio excéntrico(1949), donde se relata la vida del escritor Alfonso Karr.

\section{El contexto asistencial}

Aun con el tratamiento festivo como única perspectiva, la locura es reconocida como un trastorno y como tal necesita de una asistencia que refleje la respuesta social que su presencia suscita. El contexto asistencial más característico y más reiteradamente representado es el manicomio, lo que no deja de reflejar la realidad coetánea. La representación gráfica del manicomio es habitualmente muy elemental, reduciéndose a unos pocos bosquejos repetidos hasta conformar un arquetipo: paredes desnudas de todo lucimiento, ventanas enrejadas, puertas cerradas y altas vallas preparadas para aislar a sus moradores del exterior. A este respecto es ya muy expresiva la portada del almanaque de 1947, en que el propio Soriano se retrata dibujando tras unas rejas sobre las que se coloca el rótulo de manicomio, rodeado de un conjunto de locos a quienes apenas se les ve la cara, hacinados hasta no dejar espacio libre para poder tener otra perspectiva. El muro de ladrillo que rodea la reja y que ocupa toda la amplitud del dibujo refuerza la impresión de encierro que se transmite muy eficazmente. Las vistas del interior del manicomio suelen repetir las de un patio en que pacientes y personal a su cargo deambulan sin objeto aparente o las de corredores donde se observan puertas o ventanas invariablemente enrejadas. La desnudez del ambiente se resalta incluso textualmen- te en una historieta de Frejo en 1950, cuando un interno señala que "no tenemos nada en nuestras habitaciones, ni una miserable camita de ocho colchoncitos donde poder dormir jes intolerable!". El aspecto del manicomio resalta habitualmente el carácter carcelario de la institución: se reitera la imagen del loco asomado a lo alto de la valla, observando desde su lugar un mundo exterior ajeno, inaccesible para él, las rejas en puertas y ventanas son inevitables e incluso vemos en ocasiones en la habitación de los pacientes un cántaro con un ratón a su lado, icono que remite directamente a la representación de la mazmorra. Tales elementos no impiden que se presente el manicomio como el hogar natural del loco, siendo varias las historietas y chistes que inciden en el deseo de los propios internados de permanecer allí, buscando un refugio que les evite tener que soportar las contradicciones de la vida libre, como exclama textualmente Ciprianete, el loco idiota, personaje de Frejo en el almanaque de 1952: "¿Y si estoy loco por qué me sacaron del manicomio? ¡Guardias, que me lleven otra vez al manicomio!". Algunas veces el regreso al internamiento se expone para resolver el problema de la vivienda, acuciante en la España de los cuarenta. Otra de las imágenes arquetípicas del manicomio es la que lo representa como la materialización del caos: se trata de ilustraciones muy vistosas, en que un gran número de personajes se mezclan protagonizando cada uno su propio chiste, en actitudes tan joviales como absurdas, como en las obras de Soriano Nochevieja en Manicomiondia (1947) o de Serafín Fiesta en el Manicomio (1949).

Fuera del manicomio, son escasas las representaciones de un entorno asistencial. El tratamiento ambulatorio se muestra habitualmente en consulta privada, definida apenas por el rótulo que indica la profesión de psiquiatra. En ocasiones es el profesional quien se desplaza al domicilio del paciente. No son raras las alusiones a los elevados honorarios de las visitas. Al contrario de los internados, los enfermos ambu- 
latorios muestran un aspecto normalizado, tanto en el uso del traje como en la ausencia de expresiones de extravío o gestos inadecuados. En alguna de las escasas historietas serias, se alude al papel del psiquiatra como experto que asesora a la policía para emitir dictamen sobre el estado mental de los criminales, como en el episodio de Luis Gago La coartada, de 1947.

La labor asistencial recae necesariamente sobre un cuerpo de profesionales, identificados en todo momento como los psiquiatras, a quienes solo de forma aislada se designa como alienistas. La representación gráfica de los mismos confirma su carácter médico: en el entorno del manicomio aparecen vestidos con pijama sanitario, con bata en las consultas, donde en alguna ocasión se les ve portar un espéculo frontal, y es habitual el uso del término doctor para designarlos. Solo en una historieta de Karpa de 1950 se denomina al profesional como psicólogo. Va vestido con un elegante traje y se presenta como autor de un libro sobre psicoanálisis, atribuyéndole un estatus social elevado, como demuestra el que disponga de mayordomo en su hogar.

La representación de los psiquiatras como partícipes de la locura de sus pacientes es un lugar común en las historietas de los almanaques. A menudo su aspecto es tan estrafalario como el de los locos. En una obra de Palop de 1949, un estudiante de medicina quiere especializarse en psiquiatría, para lo que se dirige al manicomio, donde puede entrar en función de su condición médica. Allí se dirige a un sujeto vestido con pantalón corto, tocado con un gorro de papel y que empuña armas de juguete: "oiga, buen paciente, ¿podría decirme dónde está el director?", para descubrir con sorpresa que se trata del propio director de la institución. También la lógica peculiar de sus pacientes es compartida por los médicos. El mismo Palop, en sus Chispas Dementes de 1950, muestra al director del manicomio "estido con bata, pero tocado con lazo y con un chupete pendiendo de la cintura- hablando con un loco: "Tráeme un albaricoque de la despensa", le pide, "no es la época, sr director: estamos en invierno", a lo que replica "No importa; me pondré el traje de baño". Sin llegar a estos extremos, los intereses de los profesionales se presentan como ajenos al público, y con muy escasa relación con una labor terapéutica: en 1949, Soriano presenta al director del manicomio rechazando un ingreso: "¡No le admito! ¡Ya tengo tres Napoleones y lo que me hace falta es una Gilda!", mientras el psicoanalista de Karpa sale a la calle para "estudiar de cerca algunos tipos que me hacen falta".

La actitud frente a los profesionales resulta cuando menos ambivalente. Por una parte, en tanto que médicos, se les atribuye un saber y un estatus reconocido, lo que no impide ridiculizar cualquier pretensión que exceda del papel de simples guardianes, escasamente técnicos, de la locura. En el mejor de los casos, esta labor se presenta fundamentada en la caridad, como en la historieta de Pertegás El Padre Jofre, de 1949, hagiografía del fraile mercedario que exhortó a la fundación del manicomio de Valencia, que puede inscribirse en la tradición del discurso del "jofrismo" dominante en esos años (11).

Junto a los psiquiatras, los otros profesionales reiteradamente representados son los loqueros, personajes imprescindibles que encarnan definitivamente el papel de custodia policial identificado con la asistencia. De aspecto fornido, siempre vestidos con pijama sanitario, van en pareja y se les representa conduciendo a los locos al manicomio o bien en pos de los mismos, en persecuciones callejeras, conduciendo una furgoneta en cuya parte posterior hay una ventanilla enrejada. Invariablemente, sus actitudes son brutales, mostrándose complacidos al forzar a los pacientes al ingreso, acompañando su actuación de comentarios irónicos. El arquetipo es tan común que sus rasgos se repiten una y otra vez sin apenas variaciones, a pesar de ser retratados por distintos autores.

Los testimonios respecto a tratamientos 
son escasos. El rol terapéutico más definido es puramente custodialista. Las instituciones están para aislar a los pacientes, que por su propia naturaleza han de ocupar allí su lugar. Títulos repetidos como iSe ha escapado un loco! o ;Atención! ¡Estar prevenidos! ;Atención! ¡iSe han escapado cuatro locos!!, repetidos con diversas variantes, definen bien la misión asignada a la estructura asistencial y a sus responsables. No sorprende así que sean los tratamientos coercitivos los más representados: la camisa de fuerza -en muchos dibujos casi el uniforme propio del manicomio- y la celda de paredes acolchadas. Solo en la historieta realista Una ciudad manicomio, dibujada por Pertegás en 1950, se apunta la posibilidad de que el acceso de los pacientes a un cierto grado de libertad pueda resultares beneficioso. El autor relata la existencia de la ciudad belga de Gheel, donde "pasaban de tres mil los locos que con sus raras y extravagantes costumbres deambulaban por las calles y plazas libremente". Allí los enfermos son atendidos por los habitantes de la localidad, que los mantienen en sus casas particulares, dando con esta medida soporte a las actuaciones de "un instituto psiquiátrico dotado de los mejores adelantos modernos" y obteniendo con ello su fuente principal de ingresos. Aunque en la historieta se retraten las extravagancias y peculiaridades de los perturbados se insiste en que su libertad -una libertad limitada al ámbito de la localidad- no supone un peligro para el mantenimiento de las estructuras sociales y repercute en beneficio de los enfermos.

Apenas hay alusiones a otras estrategias. Una difusa indicación de "reposo y buenas atenciones" se apunta en una historia realista de 1949 como indicada para la curación (Grau). La persuasión se presenta inútil a pesar de ser defendida por el psiquiatra: " $i s u$ hijo tiene una clara inteligencia, pero presenta un complejo de alipaparismo, pero le garantizo a usted que lo curaré recluyéndolo en mi sanatorio durante tres años y poniendo en práctica mi moderno método de persuasión!" afirma el médico en la historieta Psiquiatría Moderna, que dibujó Peris en 1950. Pocas viñetas después, tales esfuerzos se revelan baldíos, y el paciente volverá a mostrar los mismos trastornos. El carácter irrecuperable de la locura y la inutilidad de las esperanzas de curación se expresan textualmente en varias ocasiones, sin que haya variación entre las historietas de 1947 y las de 1963.

Frente a estas imprecisas referencias contrasta la familiaridad que encontramos respecto al término psicoanálisis. Su penetración en la cultura popular fue desde los años treinta cada vez más evidente, tanto a través de la literatura (12) como del cine (13), y para la década de los cuarenta resultaba ya para el público un concepto familiar (14). A menudo el empleo de la palabra guarda poca o ninguna relación con el contenido de la historieta, como en los títulos Psicoanálisis de la vida (1949), de Liceras, o Psicoanálisis (1948) de Soriano Izquierdo, en que se limita a encabezar los típicos chistes relacionados con la locura sin ninguna explicación más. Por el contrario, en muchas ocasiones sí se ve al psiquiatra junto a un paciente tumbado en un diván, en una consulta privada. En los diálogos se ve a los psiquiatras hacer preguntas relacionadas con recuerdos de infancia, con la vida conyugal o con los sueños: "Para hacer su psicoanálisis, ha de contarme todos sus sueños raros y así podré diagnosticar! ¡Empiece!”, afirma el personaje de Liceras en la historieta de 1952 El Psicoanálisis ese. Con gran seguridad, los profesionales relacionan los discursos del paciente con "complejos", proporcionando consejos que juzgan infalibles para resolverlos. Sin embargo, nunca surtirán efecto, y el colofón de las historietas revela el sinsentido de esta pretensión. Ya en el inicio de la obra de Palop El cocodrilo, de 1952, se nos advierte que "el psicoanálisis es una paparrucha que no sirve más que para perturbar la mente de los que acuden a él". La actividad se presenta literalmente soporífera en una ilustración de 1952, en que el psiquiatra desplaza 
al paciente del diván, para quedar durmiendo sobre el mismo.

\section{Conclusión}

Los Almanaques de Locos constituyen una excelente fuente histórica para ayudar a entender las ideas y actitudes frente a la enfermedad mental más arraigadas en los años de la posguerra. Las representaciones de la locura tanto en la vertiente gráfica como en la literaria hunden sus raíces en arquetipos consolidados desde tiempo muy remoto, y muestran la vigencia de una tradición de pensamiento que ha sufrido escasas modificaciones a lo largo de los siglos. En la historieta Caso patente, de 1948, un loco, desde la valla del manicomio, señala a un cazador que lo absurdo de su inversión de tiempo y dinero para obtener su exigua recompensa le hace candidato e integrarse entre los propios internos. Sin apenas variación alguna, es la misma fábula del loco y el cazador que Peset Llorca recoge de Francesc Eiximenis en un texto del siglo XIV (7). Las transformaciones en la mentalidad popular siguen un ritmo lento, y las pervivencias son la norma y no la excepción. No quiere esto decir que no se incorporen, asimilados, conocimientos nuevos que pasan a formar parte del acervo de la cultura popular. El psicoanálisis es el mejor ejemplo de ello. En las historietas, este método se asocia a la introspección del paciente y a la necesidad de profundizar en el propio pasado para explicarse los conflictos presentes. Con toda su simplicidad, en tono jocoso y aún a veces despectivo, esta idea se da por sentada y no se considera necesario poner al lector en antecedentes.

Es fácil advertir que, a nuestros ojos, en los Almanaques se difunde una visión estigmatizante de los trastornos mentales. Sin embargo, hay que ser cuidadoso al juzgar esta cuestión. Leer con visión contemporánea los productos culturales del pasado nos lleva a simplificar en exceso y a una visión condescendiente desde el presente, que parece fundarse en que ocupásemos una posición privilegiada, al final de la historia. No podemos negar en los Almanaques que al menos reconocen a la locura un lugar en la sociedad. Si la risa exorciza la inquietud ante su presencia, al menos la mantiene presente entre nosotros, como parte de la vida cotidiana. Hoy, cuando esta presencia ha quedado relegada a la oscuridad de la intimidad -y del silencio- de las familias, el valor de reconocerla, aún de forma festiva, no deja de transmitirnos un soplo de aire fresco.

\section{BIBLIOGRAFÍA}

(1) Monferrer A. Les festes de folls. Valencia: Generalitat Valenciana-Consell Valencià de Cultura, 1996.

(2) Trope H. Locura y sociedad en la Valencia de los siglos XV al XVII. Valencia: Diputació de València, 1994.

(3) Porcel P. Clásicos en Jauja. La historia del tebeo valenciano. Onil: Edicions de Ponent, 2002.

(4) Cervera A. Entrevista con J Soriano Izquierdo. En: Porcel A, Porcel P. Historia del tebeo valenciano. Valencia: Prensa Valenciana, 1992

(5) González Duro E. Historia de la locura en España. Tomo III. Del reformismo del siglo XIX al franquismo. Madrid: Temas de Hoy, 1996.

(6) González Duro E. Treinta años de psiquiatría en España:1956-1986. Madrid: Ediciones Libertarias, 1987.

(7) Peset Llorca V. Terminología psiquiátrica en la Corona de Aragón durante la Baja Edad Media. En: Peset Llorca V. Estudios históricos sobre la psiquiatría valenciana. Valencia: Edicions Alfons el Magnànim, 1987.

(8) Nevado Loro A. Diccionario médico popular. Madrid: Sanofi-Synthelabo, 1992. 
(9) Porcel A. Marta y el complejo. La recepción popular del psicoanálisis en el franquismo. Rev Asoc Esp Neuropsiq 2012; 32 (113):165-180.

(10) González Duro E. Historia de la locura en España. Tomo I. Siglos XIII al XVII. Madrid: Temas de Hoy, 1994.

(11) Polo Griñán C. El jofrismo: del mito primigenio a la deformación histórica. Rev Asoc Esp Neuropsiq 1996; 16(58):313-324.
(12) Druet AC. La introducción del psicoanálisis en España a través de su representación. Ponencia presentada en el Congreso Internacional Mente, Sujeto e Historia. Ciencia y subjetividad en la cultura contemporánea. Madrid, mayo de 2011.

(13) Shortland M. Screen memories: towards a history of psychiatry and psychoanalysis in the movies. Br J His Aci 1987;67:421-452.

(14) Samuel LR. Shrink: A cultural History of Psychoanalysis in America. Lincoln, NE: University of Nebraska Press, 2013.

\section{LISTADO DE ILUSTRACIONES:}

1.- Portada Almanaque 194\%. José Soriano Izquierdo. El autor aparece dibujando en el centro de la imagen.

2.- Portada Almanaque 1949. José Soriano Izquierdo.

3.- Portada Almanaque 1950. José Soriano Izquierdo.

4.- Portada Almanaque 1951. José Soriano Izquierdo.

5.- Portada Almanaque 1952. José Soriano Izquierdo.

6.- El cocodrilo. José Palop. Almanaque de Locos 1952.

7.- Locuelo en la calle. Jesús Liceras. Almanaque de Locos 1952.

8.- Fiesta en el manicomio. Serafín Rojo. Almanaque de Locos 1949.

9.- Oro viejo del anecdotario loco. Sin firma. Almanaque de Locos 1948.

10.- Otra de locos. José Palop. Almanaque de Locos 1949.

11.- Ni son todos los que están. Jesús Liceras. Almanaque de Locos 1947.

12.- Página de Jesús Liceras. Almanaque de Locos 1952.

13.- ¡ iSe han escapado cuatro locos!! José Soriano Izquierdo. Almanaque de Locos 1948.

14.- Una ciudad manicomio. Enrique Pertegás. Almanaque de Locos 1950.

15.- Jalisco canta en Bocairente. Emilio Frejo. Almanaque de Locos 1950.

16.- Página de José Palop. Almanaque de Locos 1962. 

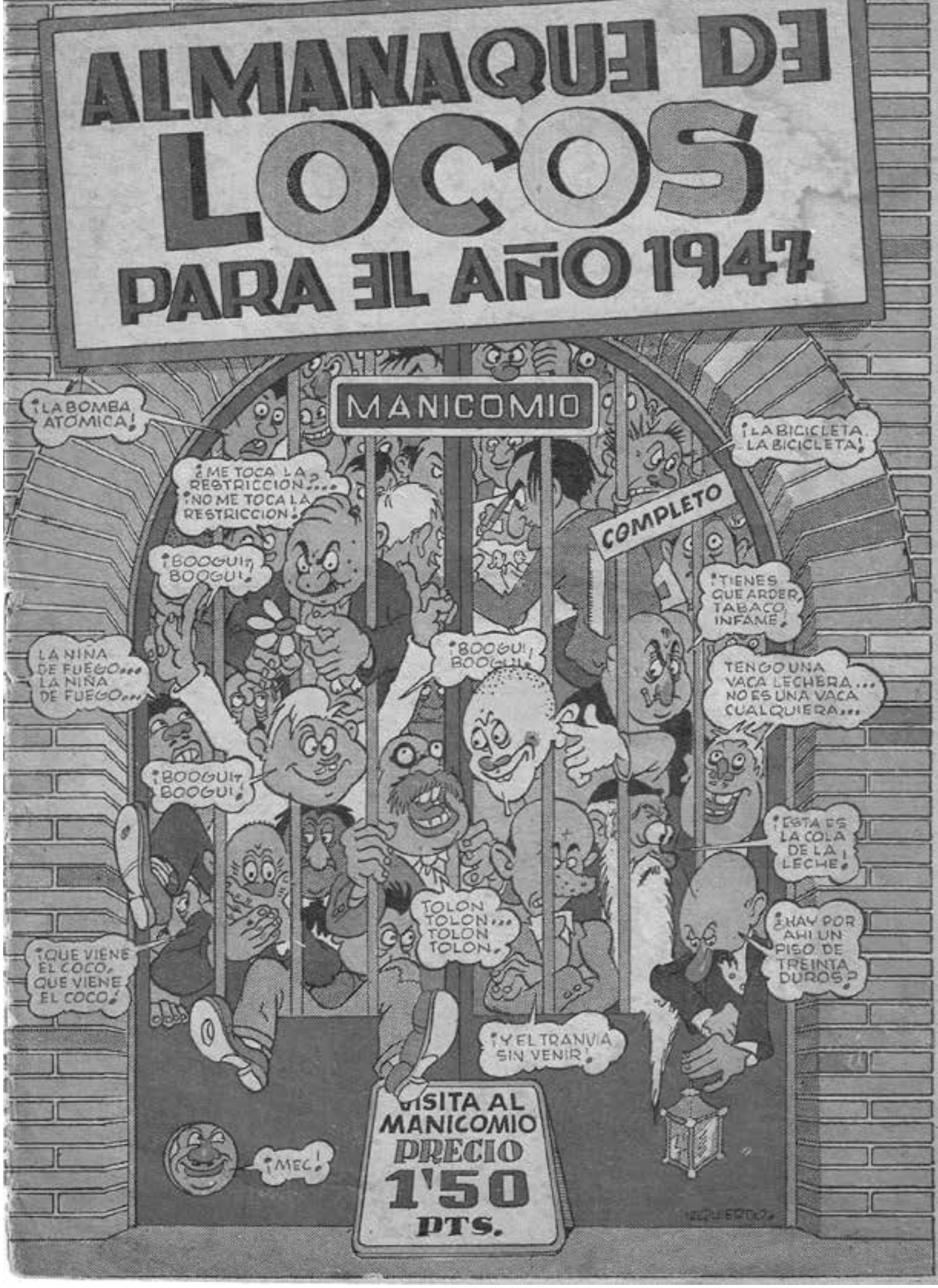

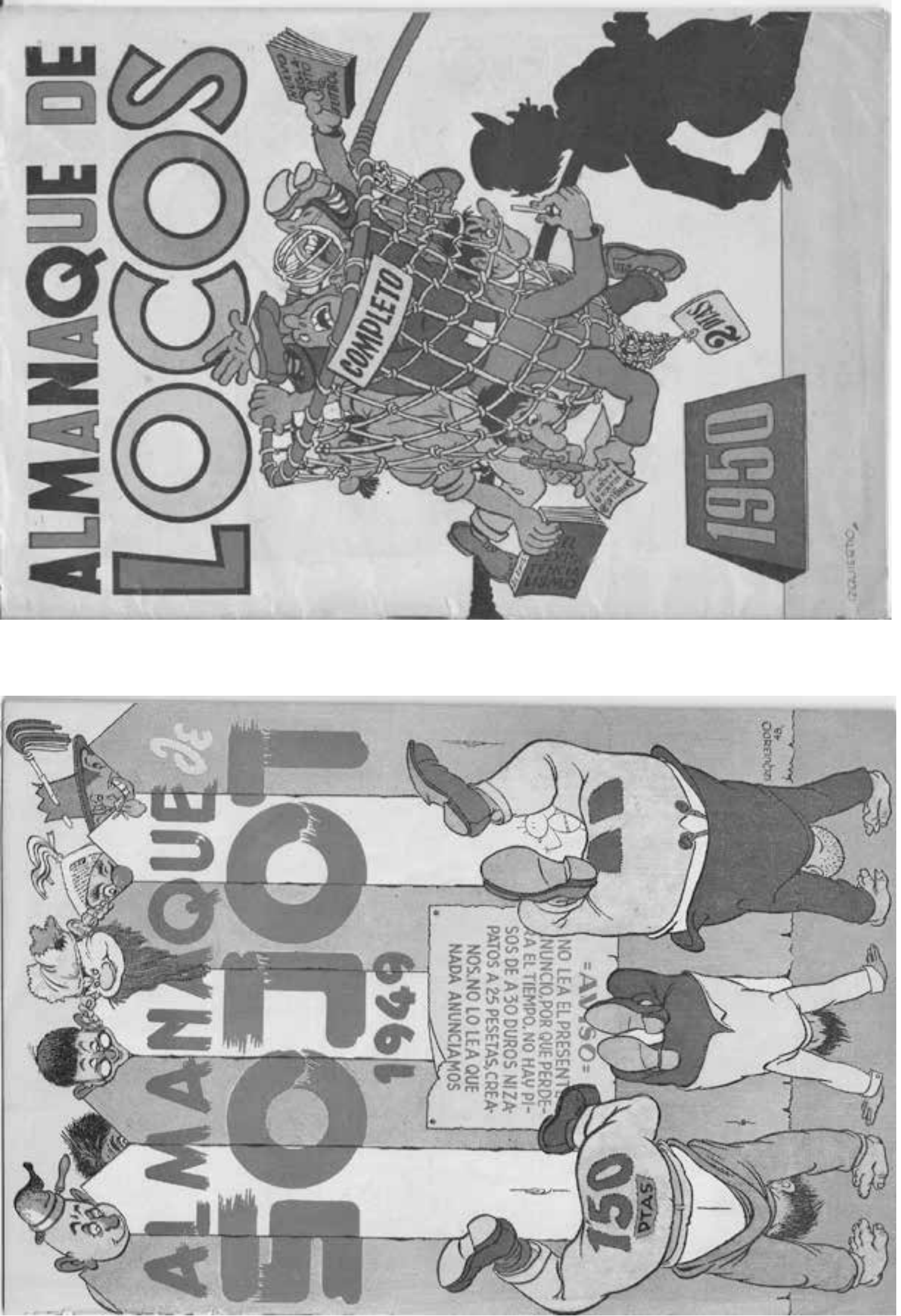

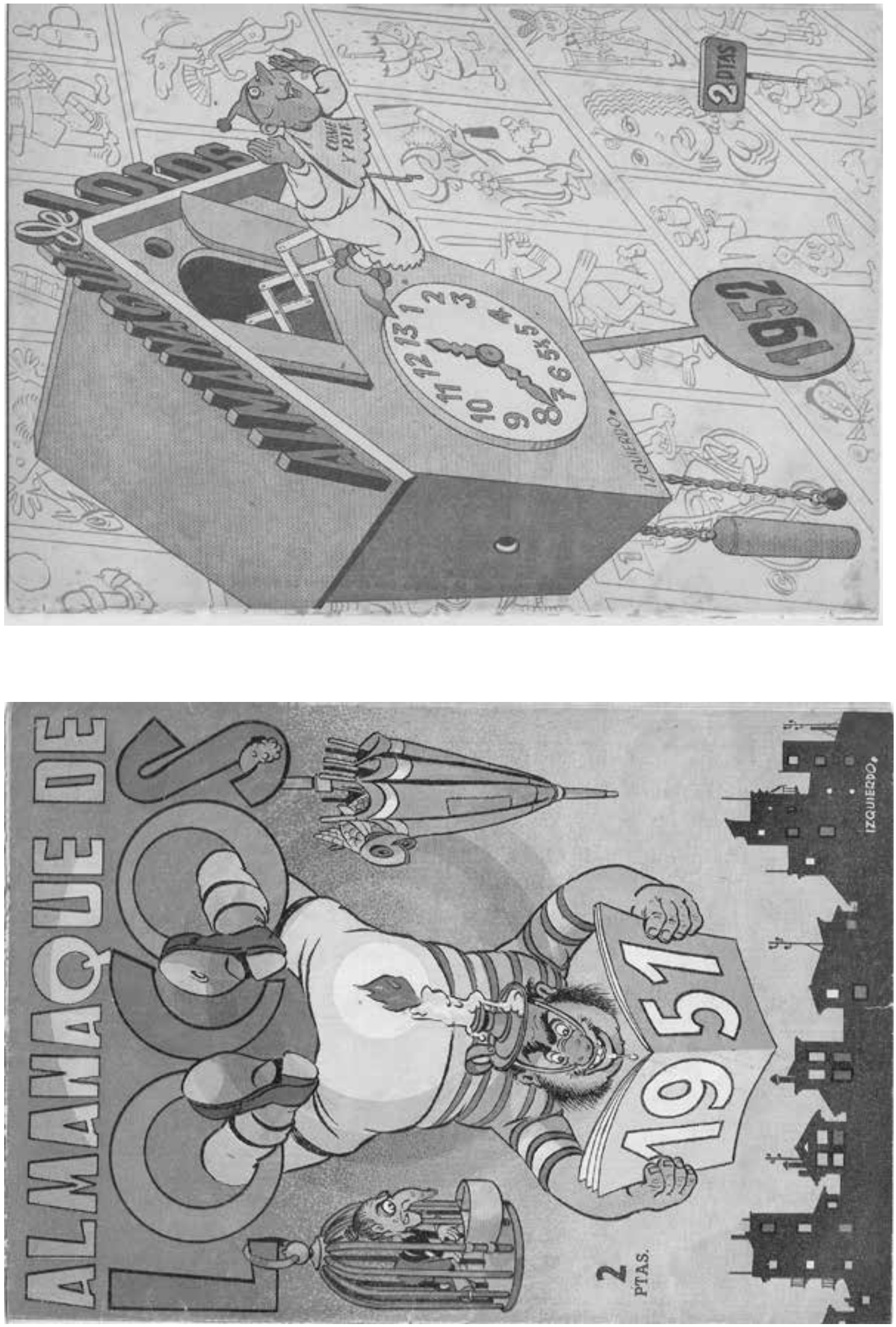


\section{EL COCODRILO}

FESO QUE ME HAS CONTADO AMLOO SIM PLICIO, ES MAS ABSURDO QUE TOMAR CA E CON TENEDOR, ANOA A CONSULTAR OM MEDICO PSICOANALISTA O ACABARA MUS DESCARSIADO QUE UNA TARTANG

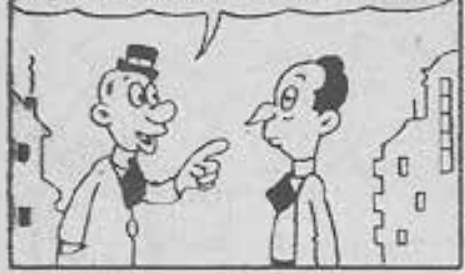

PAQ. OOCTOR: ESTOY QUE NO ME LLEGA LA CAMISA AL CUERPO. YERA: TODAS LAS MGNANAS AL OESPERTAR, OESDE H TO COCODRILO A LOS PIES DE NI CA MA QUE PARECE OECIRME: TE VOY A COMER. RESA

TPARECE.

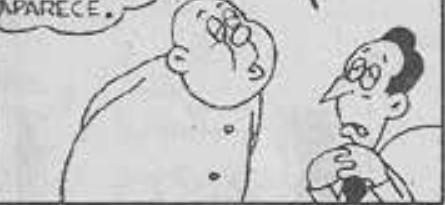

C HA VISITADO UD. EL NILO? ZILA VISTC PELICULAS DE TARZAN? $\angle$ HA LLANA. DO NLGUNA VEZ COCOORILO A SU SUEGRA ? 5T. ¿EH? AHORA CUENTEME

COSAS DE SU VIDA

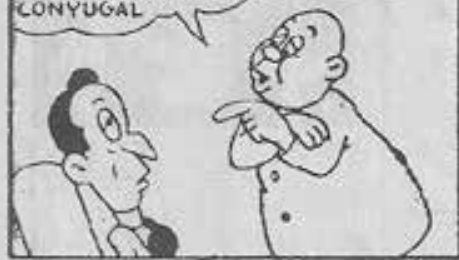

20 OUE HA VISTO UD.FS UUL VISKON

PLUSCUAMPERFECTA NADA MAS. PRO DUCIDA POR SU IMAGINACION ACOCO DRILADA. ¿ COMPRENDE?

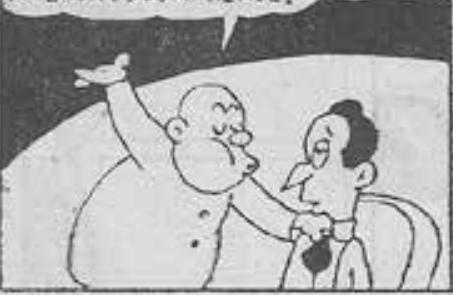

TO LO APAKTE DE LA SENDA OE LA OE MENCIA EN MENOS OUE CANTA UN BA. FTONO CON PAFERAS. PRECISAMENTE. VIVE ADUH,EN ESTA CALLE. TENGO CU. RIOSIOAD DOR VEFLE. PREGUNTEMOS

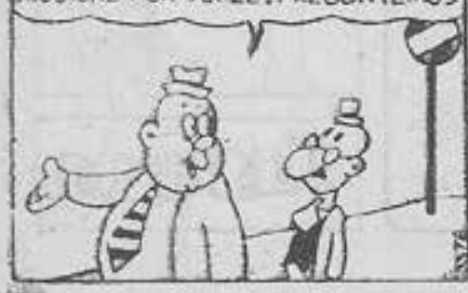

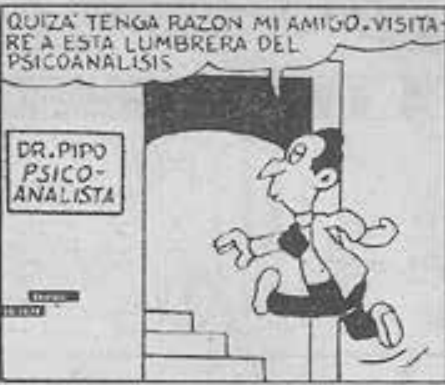

AHORA PSICOANALIZAREMOS LA COSA DIGAME. E DE CHAVAL FDE AL 200 ALGUNA VEZ? ¿ CLE ANIMAL IF IM-Y PRESIONO MAS? RECUEROE.

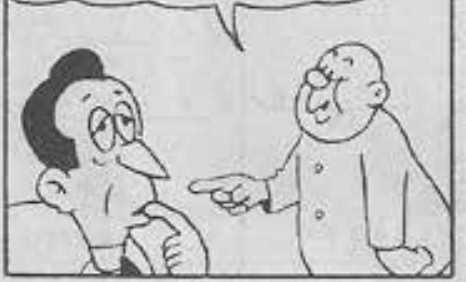

EL MES PASADO TUVE UNA OLIMPICA PELOTERA CON ME MUUER PORQUE ME NEQUE A COMPRARLE UN VALIOSO BOLSO DE PIEL DE COCODRILO. TOHO TAL BERRINCHE, QLE SE SEPARO. DE

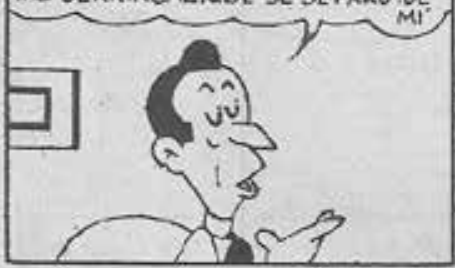

VEYASE TRANQUILO. NO $S A B E$. DOC NO HAGA CASO DE TOR. EL PESO ESAS VISIONES Y SE QUE ME QUITA CURARA. SE LO T DE LA CARTERA.
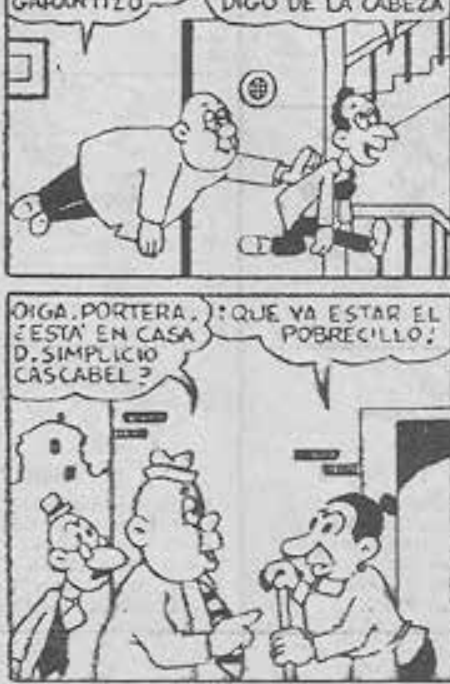

EL PSICUANALISIS ES UNA PAPARRUCHA QUE OIO SIRYE MAS OUE ALRA PERTURRAR LAMEN E OE LOS CUE ACUDEN A EL. .ILU IO CESAR

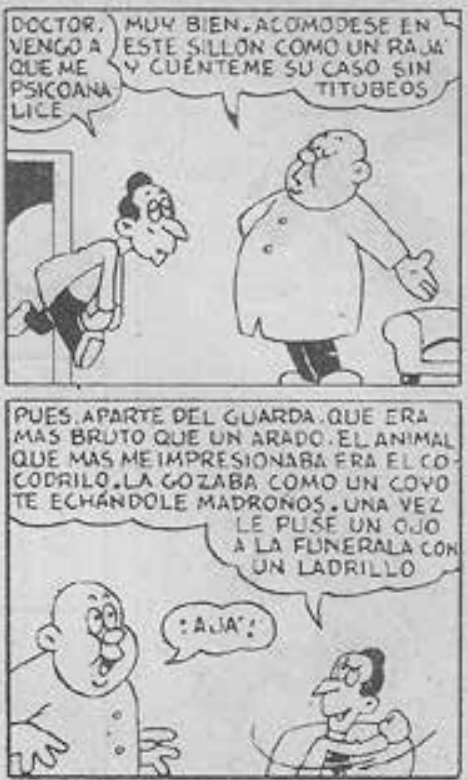

¿LO VE UD.? THOR ELLLUMO SE SAES DONDE ESTA EL FUEGO... T TIENE UD. UN SOBERANO COMPLEJO DE COCO. DRILITIS.DESTIERRELO DE SU SUE CONSCIENTE OES HOMBRE AL MANICOMIO

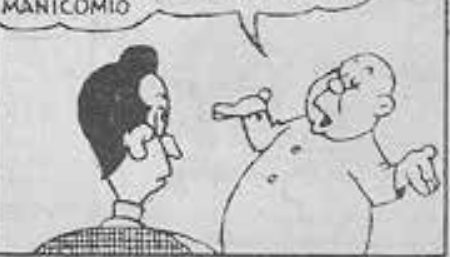

DIAS DESPUES, EL DR. PIPO... PUES SI. COLEGA. TUVE UN CASO LA MAR DE INTERESANTE: UN PACIENTT QUE CREIA YER UN COCODRILO.

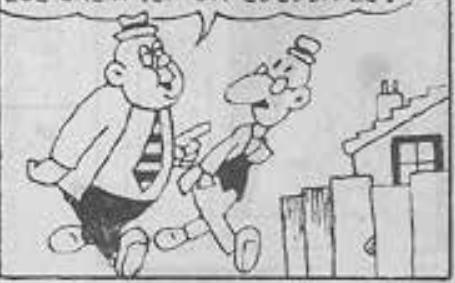

EL OTRO DA SALO UNN COCODRIIO DE BA, 0 DE LA CAMA DONDE DORMIA EL BUEN HOMBRI Y SE LO COMIO PUAMA Y TODO. DILEN QUE NO SE DEFENDTO EL INFELIZ. CREVENDO QUE EL ANMAA LUK HO ERA UNA VISION.

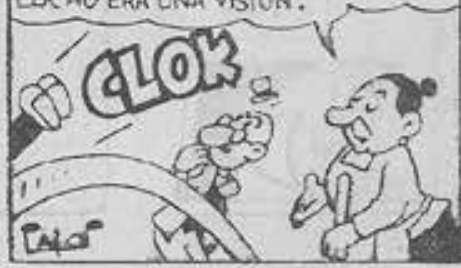




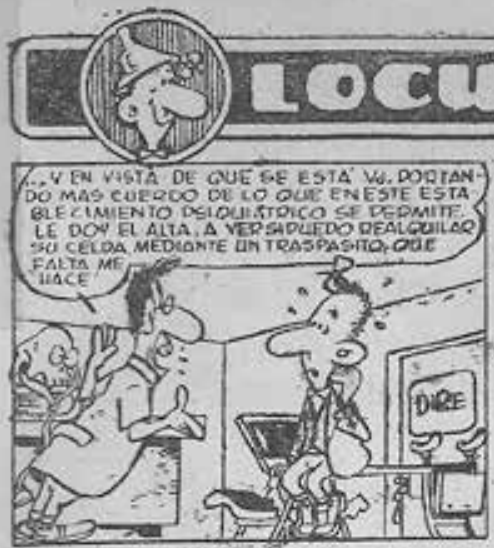

\section{ETO EN LA CALRE}
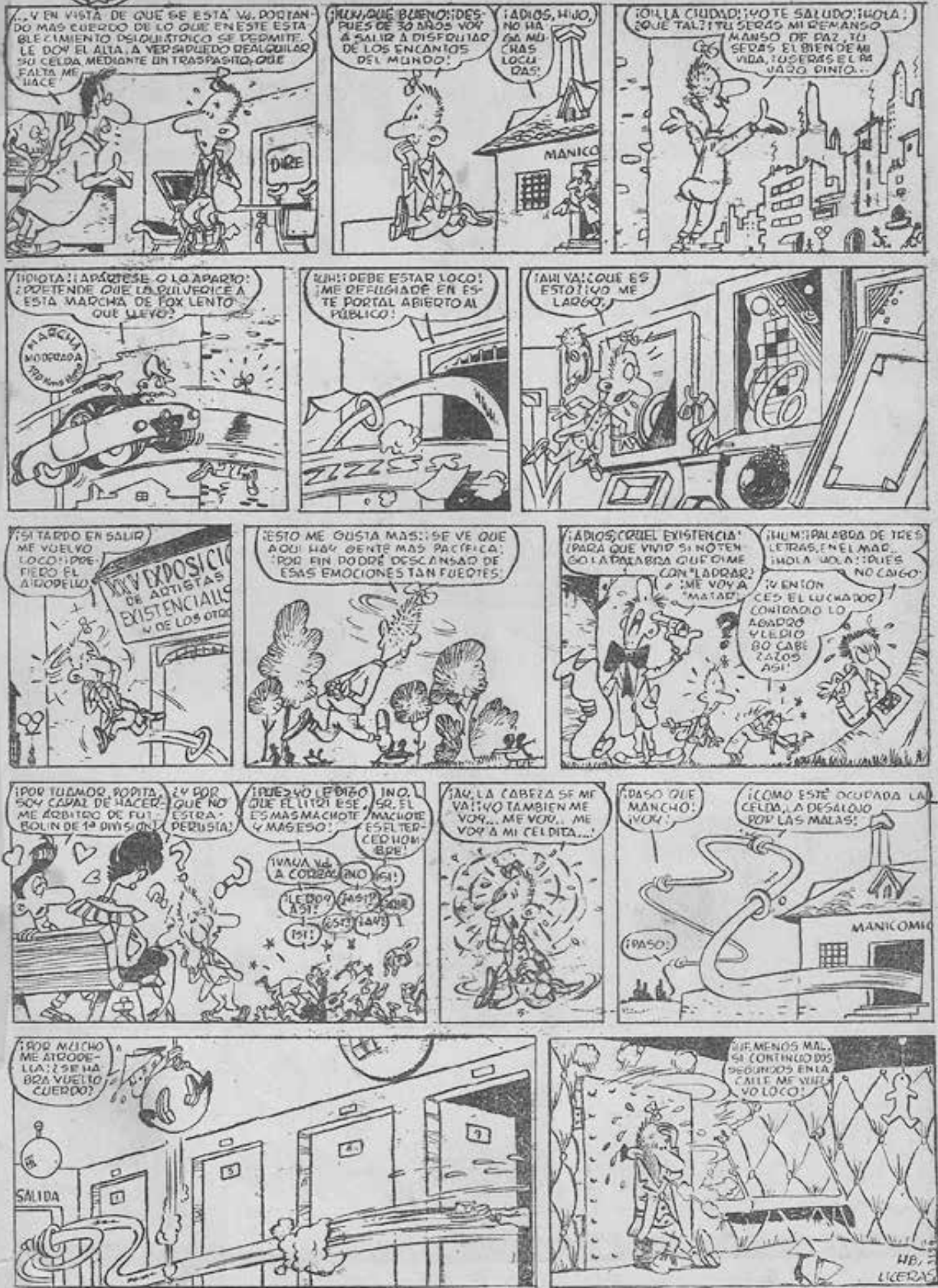


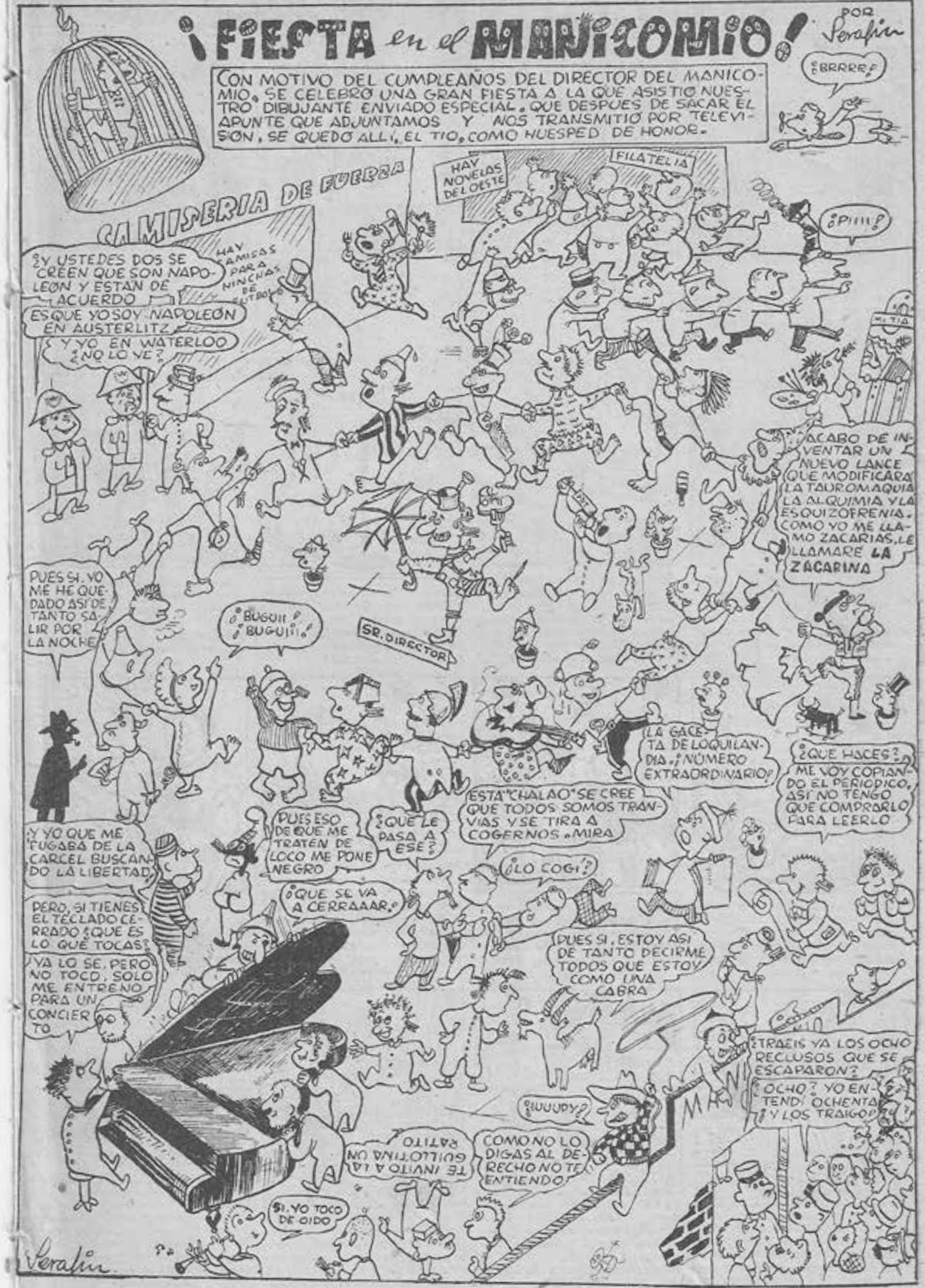




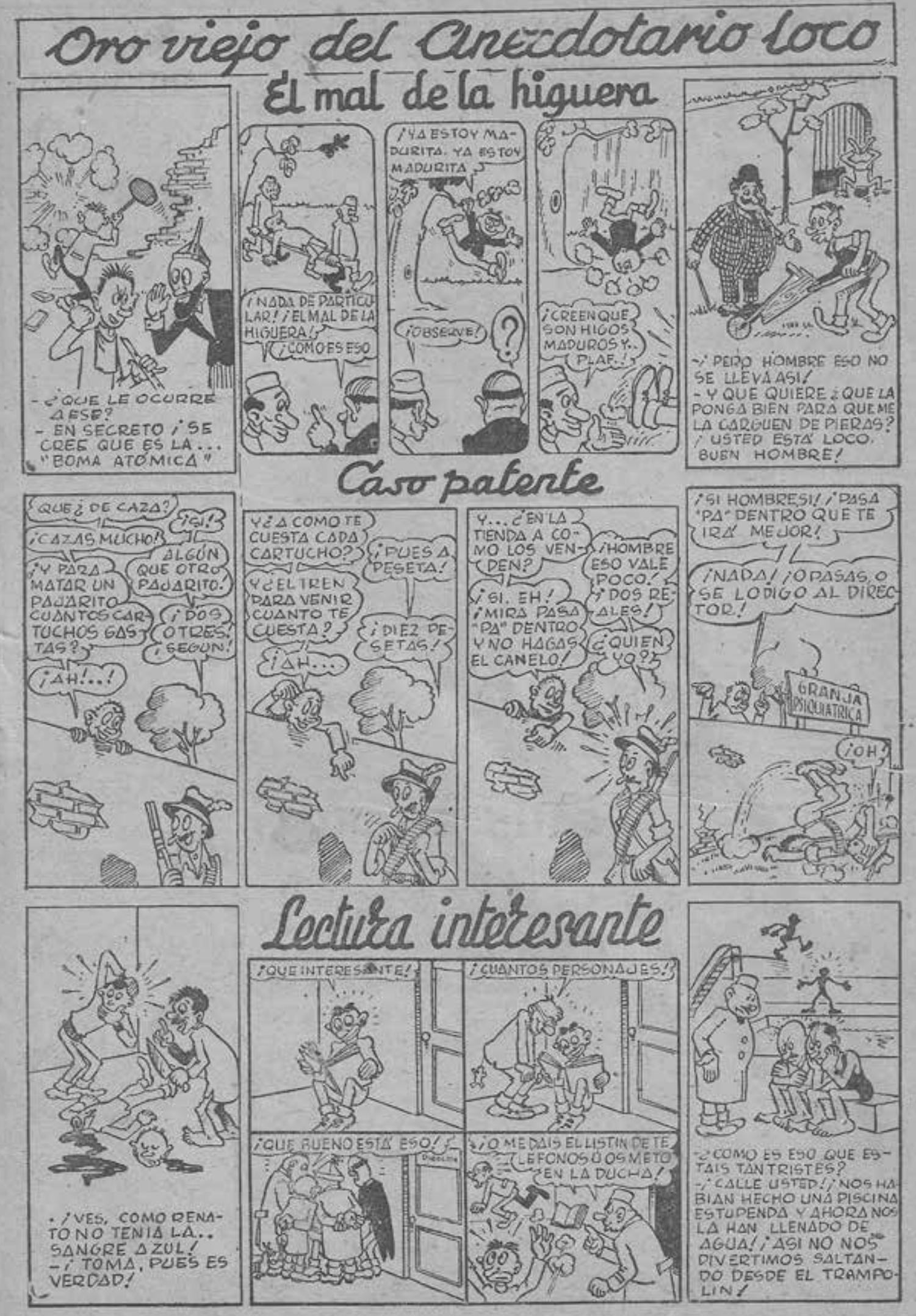



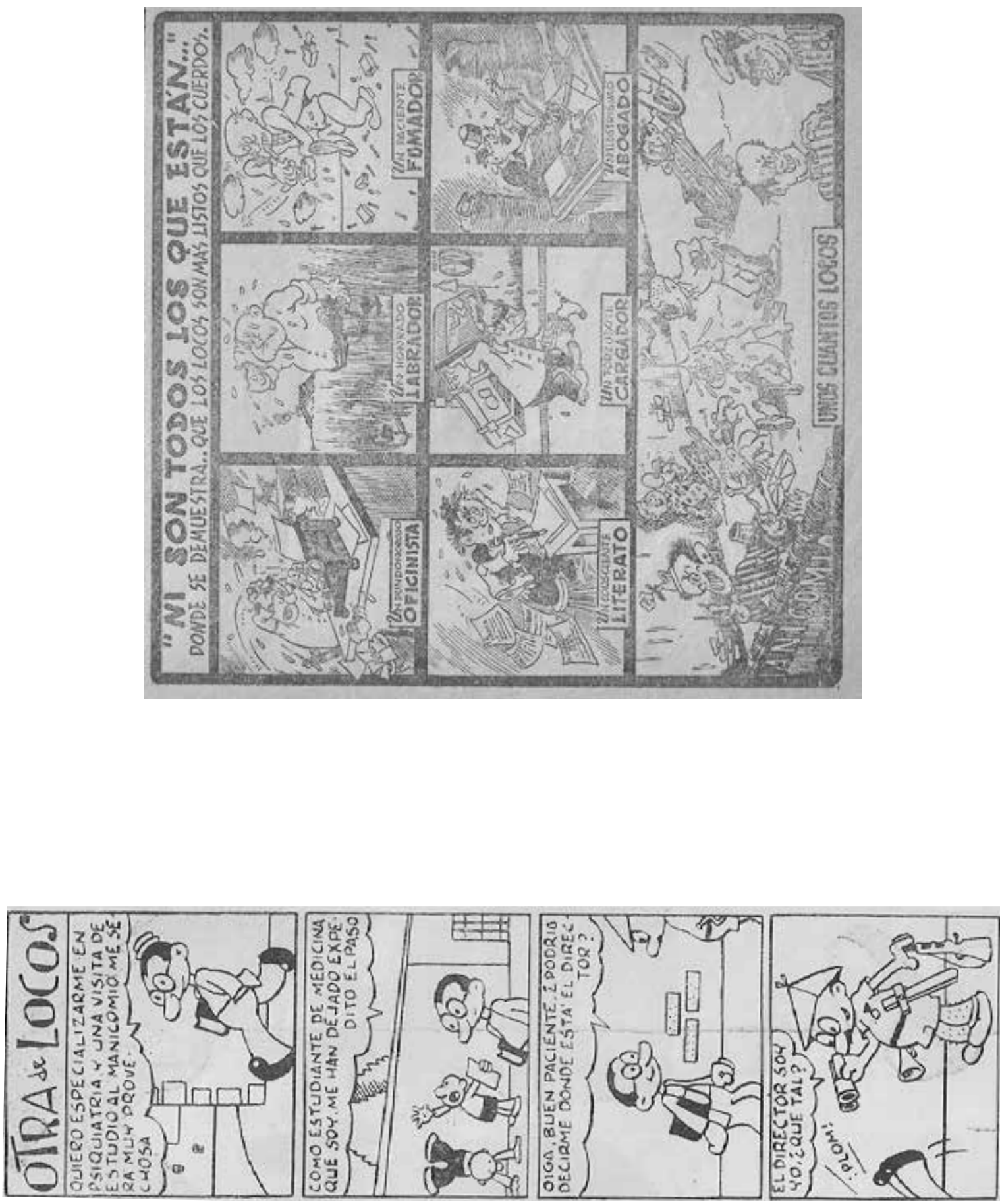


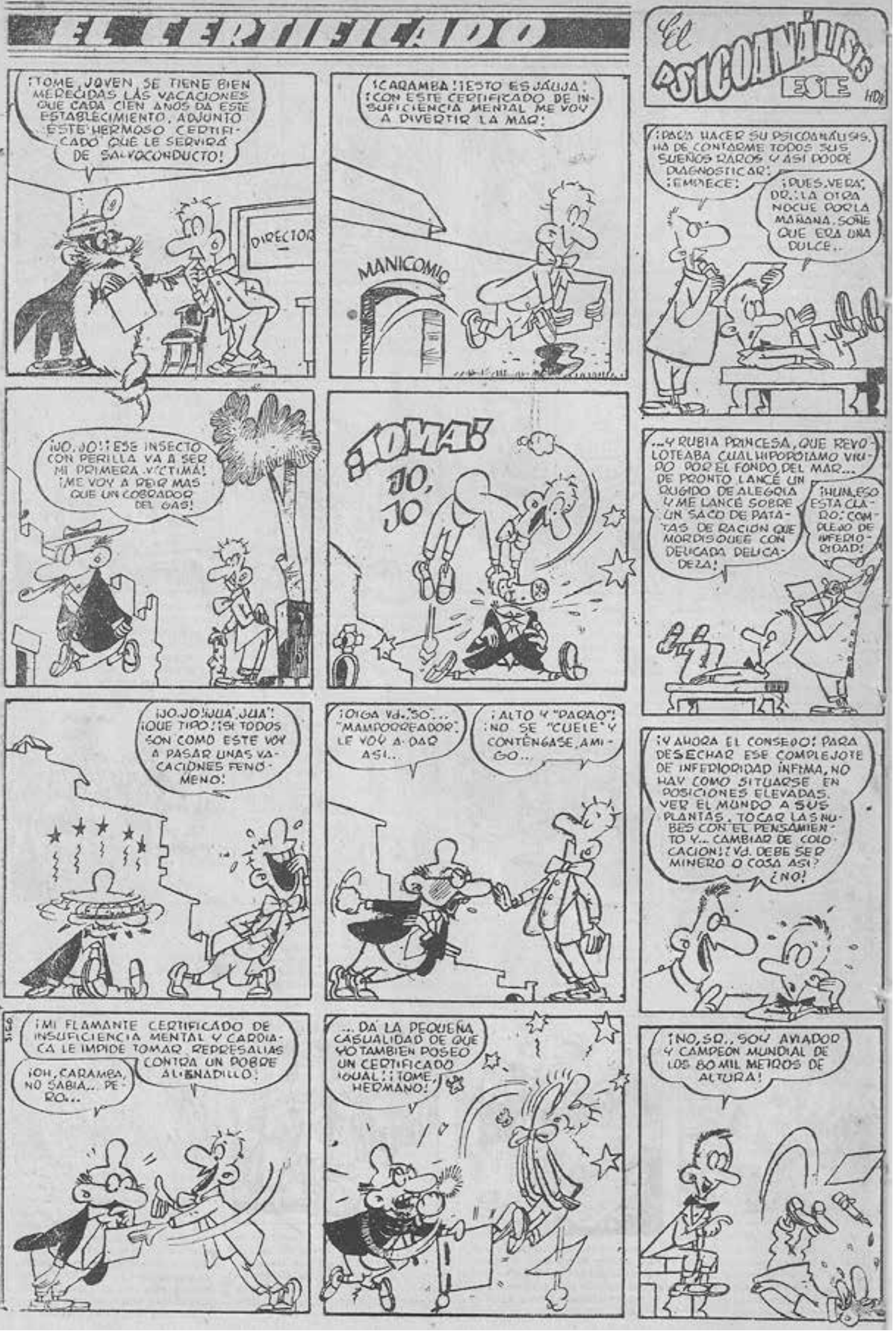




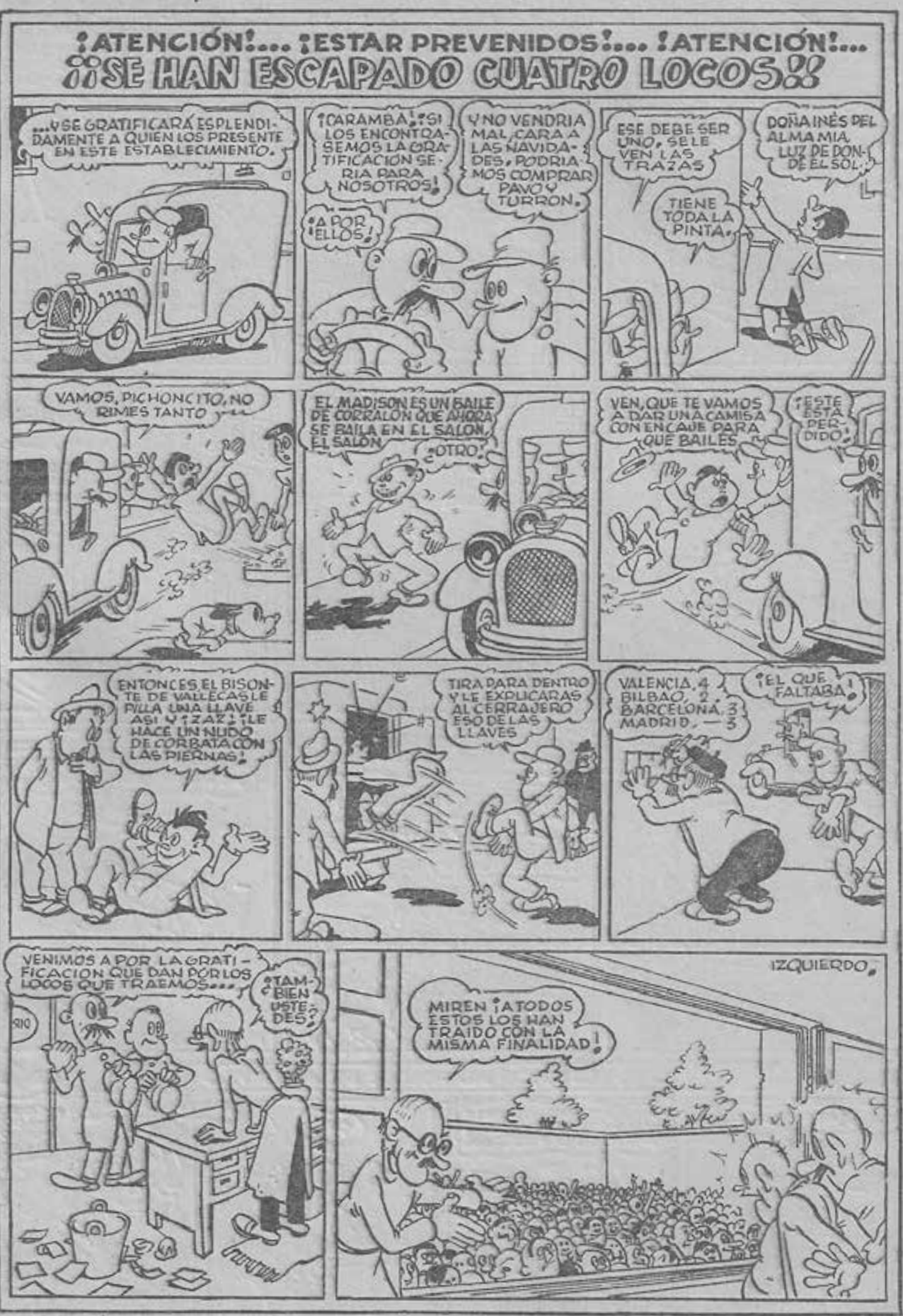




\section{UNA COOHAD MAMHCOMBO}

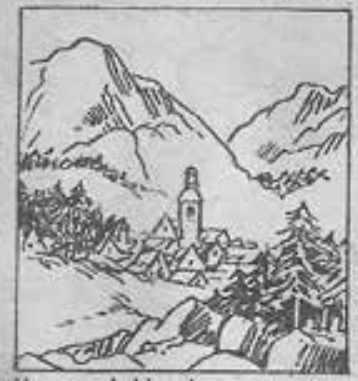

Vamos a hablar de un paqueho y pintorevco pueblecito europeo, en clavado entire hermosos y verde paisaies, que por las condiciones en ALMANAQUE DE LOCOS.

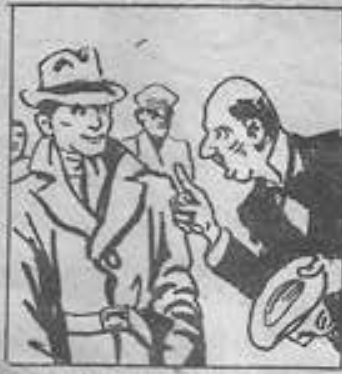

oni ti alpulen, conti gran ceremonia de corteies genuflexiones. les habla ba del plan económico de tal o cual nación para combitir la guerra co. un itran diplonátice.

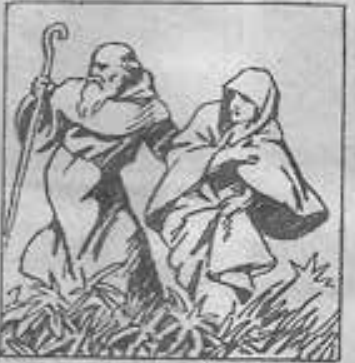

Se dice que huyendo del amor de ey de tilanda, iu propia hia Dim. fama, zcompanada de cu confesor Guereberno, busco refugio y pro in
Gocel

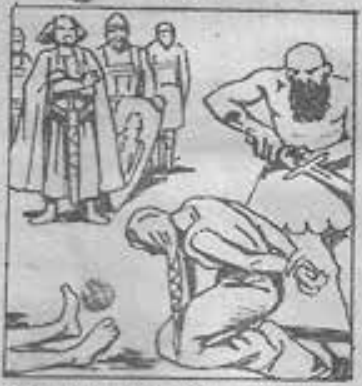

Ses por la protecriân de Suett of

per lo que fustre na fardo ea da.

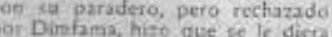

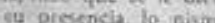

que a cipercherno

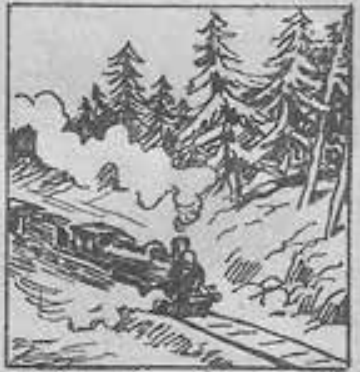

Se ilega a él por ferrocartil partiendo desde Amberes (Belgica) y desde Duisburio (Alemania). Se llama Gisel. $Y$ es famoso porqae alli en. adecuado gran cantidid de loces.

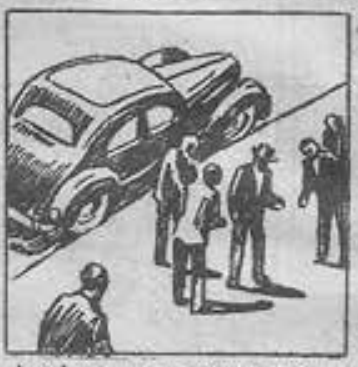

Anualmente son enviados a Cheel, ¿e distintos puntos de Europa, muchos ilestres pertarbados que por octapar elevados cargas represcenta. telectual de ta sociedad y un peligro psicuico eh las famillas.

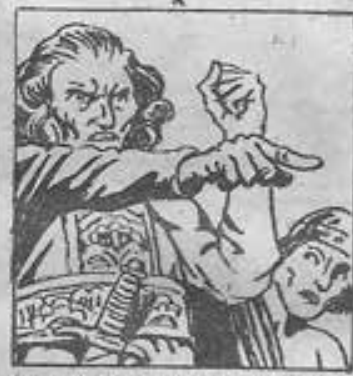

Enfurecido el sey, porcuge asi se 1 escapaba la causa que bizo arder en 14 corazon la lisma loca de in aceor irreversate, ordeob una fanática persecucton contra su his y el no hle sacerdote.

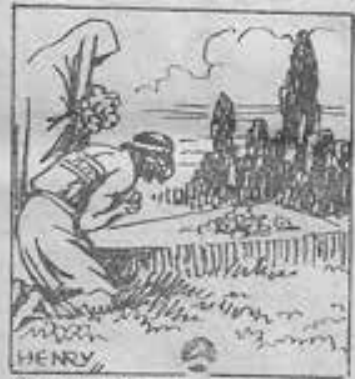

Esto vecurtis al finalisar el sipla vi

$A$ partir de entronces al cadsver de Dimfama fue ycheraco como, ina

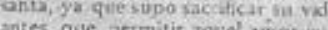
que permitir mquel tom

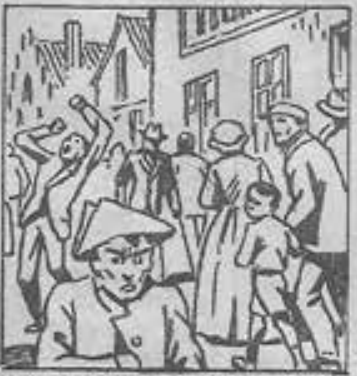

Hasta hace pocos años se stiponla que pasaban de tres mil los locos que con sus ratas y extravagantec costumbres, deambuhban por las callea y plazas de Cheel libremente, confundidos eatre sus habitantes.

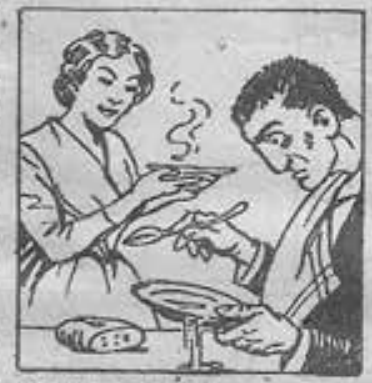

En Ghect son atendidos per sus pro. pios habitantes, que se peede decir que en esto tienien su principal fuen son retponsables de to muyoria de

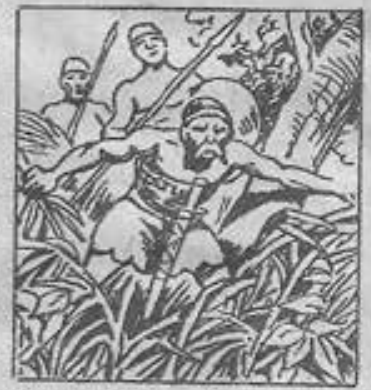

Vanos fueron las eifuerzos de lo cortesanos irlandecies por encontrar una ligera pista que les indicara el aramo a seguli para diar con el pa

adero de ha bella Dimfoma.

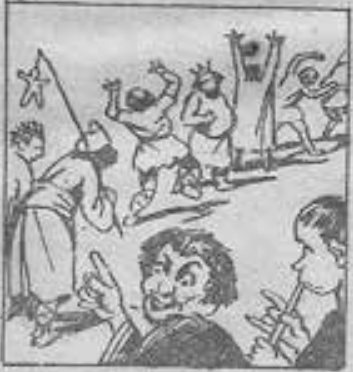

Como er aqueilos fiempos existia la tecenca de gue los locos eran seres monid, prouto aevidietion a Gheul

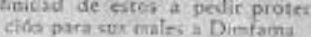

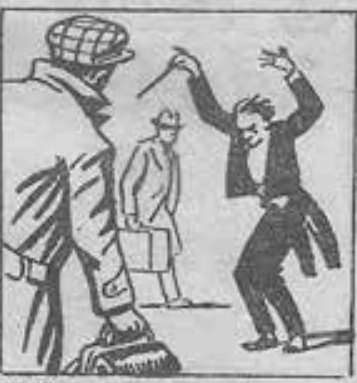

Nadie se sorprendia cuando sc apea. b) del tren, si se encontraba con un wer humano que vestido de frac cacuta en mano, creyéndose famono imaginaria prquesta

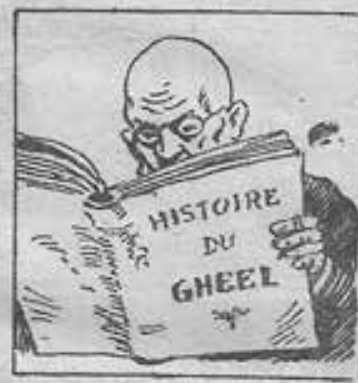

El que este humide pueblecato este dedicado a servir de crualad mila grosa pan los enajenados mutatale ranza de un toesly prosto reitabs. cimiento, tiese un legendario orisen.

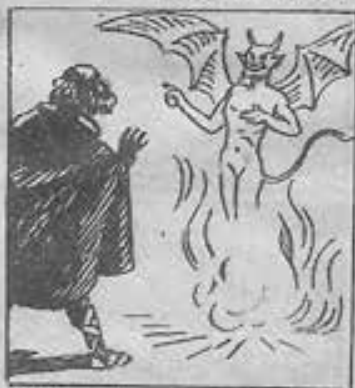

Sabedar el rey de la inutilidad de aquelia bufiquecla, desesperaito, pidione ayuda al diablo y dedicóte

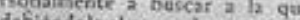

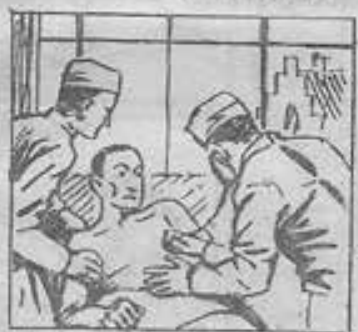

Acreditado Gheel d gobierrabel at funde un fnsticuta priquiditice en 1840 que doto de los mejore do ta certumberinos, pero respetar dos sean azendidos en las casas ma fieulates de is que podriamos lismiar 

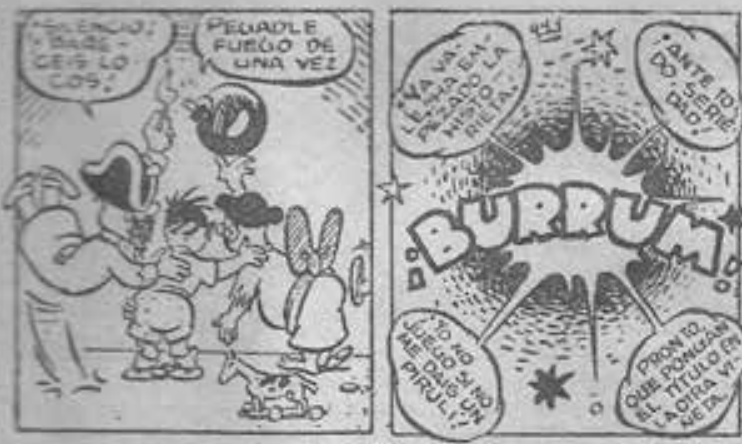

60330 BOCAIRENTE
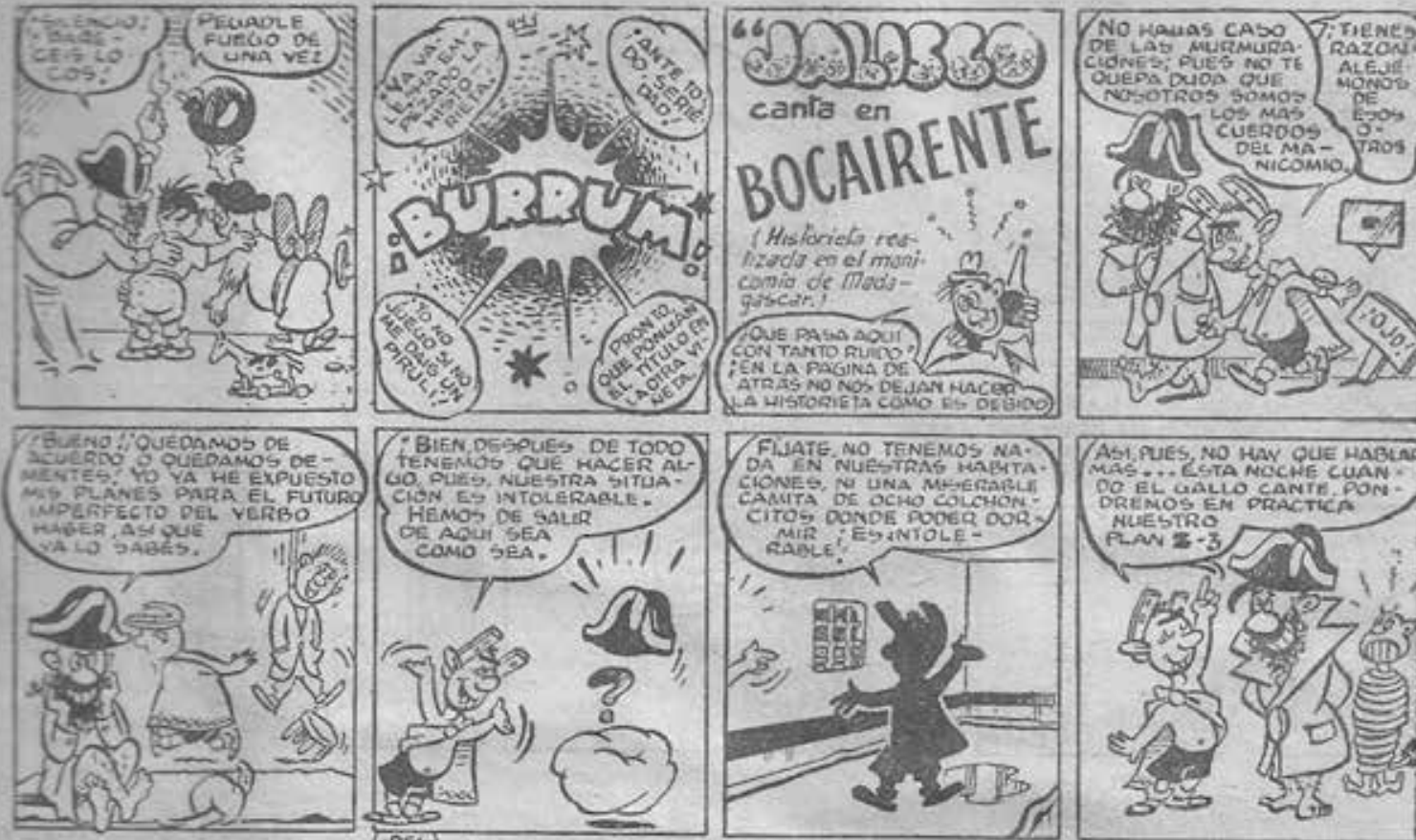

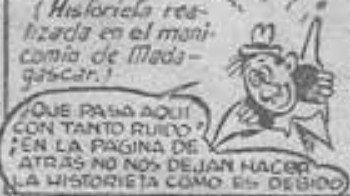
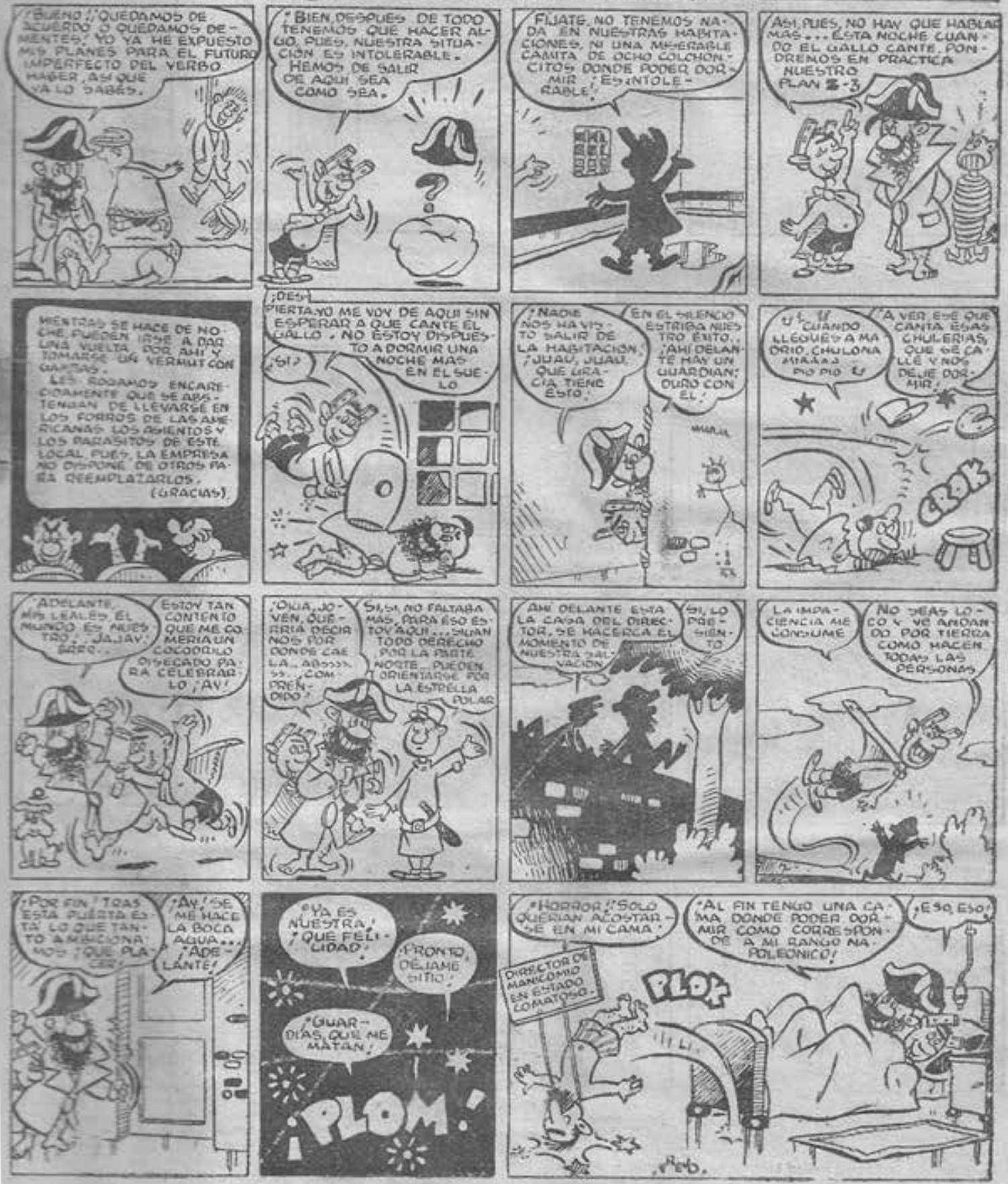


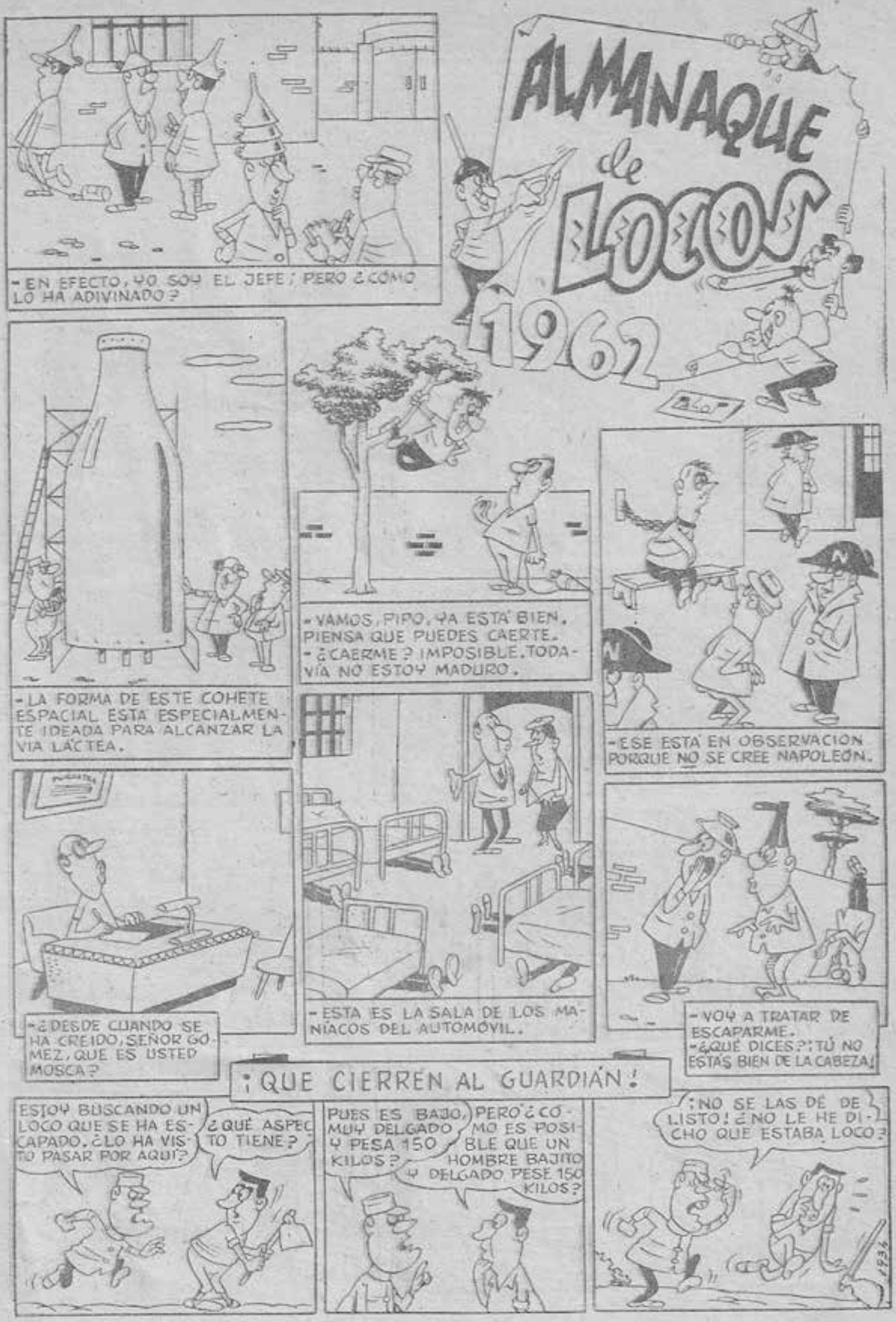

